\title{
La violencia contra la mujer y los derechos sexuales y reproductivos
}

\author{
Violeta Bermúdez Valdivia*
}

El presente artículo formula algunas reflexiones en torno a las intersecciones que existen entre la violencia contra la mujer y los derechos sexuales y reproductivos, desde un enfoque de derechos humanos. A tal efecto, analiza tres manifestaciones de violencia contra la mujer: la violencia sexual en el matrimonio, prácticas compulsivas de control reproductivo y la violación sexual como crimen de lesa humanidad. Todas ellas, implican una vulneración directa de sus derechos sexuales y reproductivos y proponen algunas experiencias positivas que pueden servir de pauta orientadora para el diseño de políticas públicas sobre la materia.

Los casos seleccionados constituyen graves atentados contra la dignidad de las mujeres, cuyos cuerpos y vidas dependen de la voluntad de los perpetradores, quienes pueden ser desde sus parejas hasta el propio Estado.

\section{Aproximaciones desde el enfoque de los derechos humanos}

En términos generales, podemos afirmar que existe un sentido común de lo que entendemos por derechos humanos. Sin embargo, cuando se trata de abordar problemas que afectan a determinados grupos de personas, especialmente aquellas que aún sufren exclusión, discriminación y violencia, muchas veces el enfoque de derechos humanos no es tomado en cuenta para diseñar políticas orientadas a enfrentar las situaciones que las afectan.

* Abogada, experta en temas de género, políticas públicas y Derecho Constitucional. Profesora de la Facultad de Derecho de la Pontificia Universidad Católica del Perú. 
Una definición de consenso establece que los derechos humanos son «un conjunto de facultades e instituciones que, en cada momento histórico, concretan las exigencias de dignidad, la libertad y la igualdad humanas» ${ }^{1}$. La preocupación por los derechos humanos tiene su referente histórico en el movimiento político y cultural surgido en Francia en el contexto de la revolución francesa y que condujo a la adopción de la Declaración de los Derechos del Hombre y del Ciudadano en 1789. Desde entonces, esta preocupación se ha traducido en la búsqueda del reconocimiento de los derechos humanos tanto en los ordenamientos jurídicos nacionales como por los organismos internacionales de protección de los mismos.

En este esfuerzo, un paso importante para el campo de la promoción, protección y vigencia de estos derechos ha sido su constitucionalización. Precisamente, a partir de la experiencia alemana y gracias al desarrollo del constitucionalismo europeo se introduce el concepto de derechos fundamentales que expresa la positivización de los derechos humanos en los textos constitucionales. De esta manera, se coloca en la cúspide de los ordenamientos jurídicos nacionales a los derechos fundamentales que «son los derechos naturales democráticamente constitucionalizados acompañados de las notas distintivas de eficacia directa y vinculación a los poderes públicos, indisponibilidad para el legislador en su contenido esencial, control judicial y control de constitucionalidad $»^{2}$. Esta consagración constitucional de los derechos humanos, otorgará la posibilidad de exigir a un tercero — poder público o un particular — el cumplimiento de un deber de actuar o de abstenerse de hacerlo ${ }^{3}$.

Otro aspecto importante a tener en cuenta es el carácter evolutivo y dinámico de los derechos humanos. En este marco, resulta didáctico recurrir al criterio histórico o cronológico de los derechos humanos; es decir, a las generaciones de derechos:

- Los derechos de primera generación o derechos civiles y políticos, que responden al valor libertad.

Perez Luño, Antonio Enrique. Derechos Humanos, Estado de Derecho y Constitución. Tercera edición. Madrid: Tecnos, 1990, p. 48.

Perez Royo, Javier. Curso de Derecho Constitucional. Madrid: Marcial Pons, 2000, p. 283.

3 Bastida Frejuedo, Francisco J. y otros. Teoría General de los Derechos Fundamentales en la Constitución Española de 1978. Primera edición 2004, reimpresión 2005. Madrid: Tecnos, 2005, pp. 32-33. 
- Los derechos de segunda generación o derechos económicos, sociales y culturales, que responden al valor igualdad.

- Los derechos de tercera generación, vinculados a la libertad igualitaria y el valor solidaridad ${ }^{4}$.

Este esquema de las generaciones, reconocido y utilizado en la teoría de los derechos humanos — aunque actualmente superado- tiene el mérito resaltar a los derechos humanos como una categoría histórica; es decir, que reconoce que estos surgen en un contexto y debido a circunstancias concretas. En suma «son producto del esfuerzo humano por encontrar unas reglas básicas de convivencia para todos» ${ }^{5}$.

El carácter evolutivo y dinámico de los derechos humanos, nos ayuda a comprender también la progresiva inclusión de nuevos titulares de los mismos. Dentro de ellos, podemos ubicar a las mujeres, cuyos derechos en la agenda de los derechos humanos han merecido un tratamiento especial en las últimas décadas, fundamentalmente luego de la adopción de la Convención sobre la eliminación de toda forma de discriminación contra la mujer, en 1979.

De otro lado, los derechos humanos se han convertido hoy en un sólido pilar para la difusión de la conciencia democrática universal y representan una suerte de base jurídica para la generación de un ambiente mundial de desarrollo sostenido, de justicia social y no discriminación ${ }^{6}$, valores compartidos por los Estados parte de las Naciones Unidas. Desde esta perspectiva, la filosofía de los derechos humanos ha ido impregnando los diversos escenarios de promoción y protección de los derechos de todas las personas, incluidas las mujeres.

En efecto, en la actualidad no resulta extraño constatar la progresiva preocupación de los organismos nacionales e internacionales por lograr la plena vigencia y el respeto de los derechos de las mujeres. Es más, al

4 Otros autores identifican cuatro generaciones de derechos desdoblando la primera de ellas en: i) primera: derechos civiles y segunda: derechos políticos.

5 Martinez de Pison, José. «Las generaciones de derechos humanos». En Constitución y Derechos Fundamentales. Madrid: Centro de Estudios Políticos y Constitucionales, 2004, p. 412.

6 Bernales B., Enrique. «Sistema Internacional de Protección de los Derechos Humanos de las Mujeres». En Derechos Humanos de las mujeres. Aportes y reflexiones. Serie Mujer y Derechos Humanos 6. Lima: Movimiento Manuela Ramos, 1998. 
interior de los Estados se han venido aprobando normas, implementando políticas públicas y creando una serie de instancias encargadas de velar por estos derechos. Tampoco resulta extraño encontrar dispositivos constitucionales que recogen explícitamente derechos de las mujeres como el de la igualdad, el derecho a su participación política, el derecho a estar libre de violencia y otros derechos vinculados a la sexualidad y reproducción.

No obstante lo indicado, conviene analizar cómo ha sido tomado en cuenta el enfoque de derechos humanos en el tratamiento de uno de los problemas más dramáticos que afronta la mitad de la humanidad; es decir, la violencia contra la mujer.

\section{La violencia contra la mujer, un problema de derechos humanos}

Si bien hoy se puede afirmar categóricamente que la violencia contra la mujer es un problema de derechos humanos y por lo tanto, los Estados y la sociedad en general tienen responsabilidades que reportar a sus nacionales y a la comunidad internacional respecto de su prevención, sanción y erradicación; conviene tener presente que estamos ante un reconocimiento relativamente reciente.

No fue sino hasta la II Conferencia Mundial sobre Derechos Humanos, realizada en Viena en 1993, en que la Organización de las Naciones Unidas recordó a los Estados que la violencia contra la mujer es una violación de los derechos humanos, subrayando la importancia de eliminarla tanto en sus manifestaciones en la vida pública y privada; así como de eliminar todas las formas de acoso sexual, la explotación y la trata de mujeres ${ }^{7}$.

A partir de aquel momento, que puede ser calificado como un hito en el reconocimiento de los derechos humanos de las mujeres - y de los derechos humanos en general - se han venido produciendo una serie de avances institucionales y normativos a nivel mundial. Precisamente, el primero de diciembre de 1993, en el cuadragésimo séptimo período de sesiones de la Asamblea General de las Naciones Unidas se proclamó la Declaración sobre la Eliminación de la Violencia contra la Mujer y se instó a los Estados

7 «Conferencia Mundial de Derechos Humanos: Declaración y Programa de Acción de Viena». Viena: Naciones Unidas, junio 1993, p. 58. 
parte a que hicieran todos los esfuerzos posibles para que sea universalmente reconocida y respetada.

Este importante instrumento internacional define la violencia contra la mujer como:

Todo acto de violencia basado en la pertenencia al sexo femenino que tenga o pueda tener como resultado un daño o sufrimiento físico, sexual o psicológico para la mujer, inclusive las amenazas de tales actos, la coacción o la privación arbitraria de la libertad, tanto si se producen en la vida pública como en la privada. (Declaración sobre la Eliminación de la Violencia contra la Mujer, artículo 1)

Por tanto, esta definición permite considerar como violencia contra la mujer a: i) el evento mismo de la violencia o la amenaza de su perpetración; ii) los actos o amenazas de violencia producidos en el ámbito público o privado; iii) los perpetrados por el Estado o por particulares.

En el plano regional es la Convención Interamericana para prevenir, sancionar y erradicar la violencia contra la mujer ${ }^{8}$, aprobada por la Asamblea General de la Organización de Estados Americanos (OEA) en junio de 1994, la que nos da una clara definición de lo que debe entenderse por violencia contra la mujer:

Para los efectos de esta Convención debe entenderse por violencia contra la mujer cualquier acción o conducta, basada en su género, que cause muerte, daño o sufrimiento físico, sexual o psicológico a la mujer, tanto en el ámbito público como en el privado. (Artículo 1)

Además de esta definición, la Convención amplía los alcances de la violencia contra la mujer. Así considera a la que pueda producirse:

- En la familia o unidad doméstica o cualquier otra relación interpersonal, ya sea que el agresor comparta o haya compartido el mismo domicilio que la mujer, y que comprende, entre otros, violación, maltrato y abuso sexual;

- En la comunidad y sea perpetrada por cualquier persona, comprendiendo entre otras formas de violencia, violación, abuso sexual, tortura, trata de personas, prostitución forzada, secuestro y acoso

8 En adelante, Convención contra la violencia a la mujer. 
sexual en el trabajo, así como en instituciones educativas, establecimientos de salud o cualquier otro lugar; $y$,

- Por el Estado o sus agentes dondequiera que ocurra o la que sea tolerada por los mismos.

La Plataforma de Acción de la IV Conferencia Mundial sobre la Mujer (Beijing, 1995) incluyó a la violencia contra la mujer entre las doce esferas de especial preocupación. En los debates de dicha conferencia se mencionaron diversas formas de agresión sexual que no se habían mencionado específicamente en la Declaración: la violación sistemática y los embarazos forzados durante los conflictos armados, la esclavitud sexual, la esterilización forzada y el aborto forzado, el infanticidio de nińas y la determinación prenatal del sexo?.

De otro lado, la consideración internacional de la violencia contra la mujer como una violación de los derechos humanos se vio reflejada en la designación, en 1994, de una Relatora especial sobre la violencia contra la mujer, sus causas y sus consecuencias. La primera designación recayó en Radhika Comaraswamy de Sri Lanka, quien ejerció el cargo hasta 2003. A partir de agosto de aquel año, se nombró a Yakin Ertürk de Turquía como la Relatora Especial. Precisamente, esta última, en su primer informe presentado a la Comisión de Derechos Humanos ${ }^{10}$ propone una ampliación del ámbito conceptual de las distintas categorías de la violencia contra la mujer.

A partir de la definición de la Declaración, la Relatora sostiene que las tres grandes categorías que contiene esta definición (violencia en la familia, en la comunidad y la perpetrada y tolerada por el Estado) requieren ser ampliadas conceptualmente con el objetivo de abarcar a las situaciones de violencia contra la mujer que se dan desde el hogar hasta el ámbito transnacional. La Relatora llama, de manera especial, la atención sobre las siguientes categorías:

9 Naciones Unidas, Consejo Económico y Social. «Integración de los derechos humanos de la mujer y la perspectiva de género: la violencia contra la mujer». Informe de la Relatora Especial sobre la violencia contra la mujer, sus causas y sus consecuencias, Yakin Ertürk. Comisión de Derechos Humanos $60^{\circ}$ período de sesiones. E/CN.4/2004/66, 26 de diciembre de 2003, p. 9.

10 lb., pp. 13-14. 
- La violencia en el hogar, que comprende en general todos los actos de violencia contra la mujer que se producen y perpetúan en la intimidad del hogar. En este campo, señala la Relatora, no se ha prestado suficiente atención a la violencia contra la mujer en las relaciones familiares; así como tampoco a la situación de las empleadas o trabajadoras del hogar, que muchas veces son víctimas de humillaciones, explotación y diversas formas de violencia extrema.

- La violencia que se produce en el ámbito transnacional; es decir, la que se produce más allá de los límites de un Estado. Al respecto, se ha observado que con el cierre de fronteras ha aumentado el problema de la trata de mujeres con fines de explotación sexual y económica, situación que incrementa los riesgos de violencia contra ellas.

Esta ampliación conceptual explicita igualmente la necesidad de integrar un análisis de género al problema de la violencia contra la mujer, pues estamos ante una manifestación de relaciones de poder históricamente desiguales entre el hombre y la mujer, que ubican en una situación de subordinación a esta última. Por tanto, «la violencia se ha utilizado como mecanismo legítimo para aplicar y mantener ese sistema de dominación», afirma la Relatora ${ }^{11}$.

En los planos nacionales, los Estados han venido aprobando progresivamente leyes y diseñando políticas públicas para enfrentar algunas manifestaciones de violencia contra la mujer, particularmente en el ámbito familiar. Así, se han aprobado leyes especiales para abordar la violencia familiar contra las mujeres en la mayoría de países de América Latina, aunque todavía con relativo éxito ${ }^{12}$.

\footnotetext{
lb., p.11.

12 Todos los países de nuestra región que han adoptado una legislación especial para regular la violencia contra la mujer, lo han hecho dentro de una legislación más amplia sobre violencia en la familia. El objetivo de todas estas leyes es la protección de los integrantes del grupo familiar - conviviente o no-, frente a cualquier forma de violencia que se produzca en el contexto de las relaciones familiares. Sin embargo, los datos oficiales de registro de este tipo de agresiones informan que, en todos los países, las víctimas «por excelencia» en estos casos son mujeres y, en consecuencia, las usuarias de esta normatividad pertenecen a este grupo humano. Cfr. BERMúdEZ, Violeta. Módulo Legislativo sobre Violencia contra la Mujer. Herramientas Conceptuales. Grupo Parlamentario Interamericano sobre Población y Desarrollo. New York, 1997.
} 
En suma, es indudable que los Estados tienen una importante responsabilidad en prevenir, investigar y sancionar los actos de violencia contra la mujer, repudiados explícitamente por la comunidad internacional y por sus propias normas internas ${ }^{13}$. Estamos pues ante un problema grave de violación de los derechos humanos.

\section{Alcances de los derechos sexuales y reproductivos}

Otro tema de preocupación de la comunidad internacional es el vinculado a la dramática situación por la que atraviesan muchas mujeres como resultado de las restricciones al libre ejercicio de su sexualidad y de sus capacidades reproductivas. En efecto, si bien no existen instrumentos internacionales específicos que vinculan a los Estados respecto al reconocimiento y respeto de los derechos sexuales y los derechos reproductivos, las Conferencias de El Cairo (1994) y Beijing (1995) han tenido un impacto importante en la ruta hacia el reconocimiento de los mismos. Incluso, se afirma que desde entonces, por primera vez, los órganos y agencias del sistema de Naciones Unidas han comenzado a trabajar, aunque en diverso grado, en la manera de integrar los derechos sexuales y los derechos reproductivos. Así lo vienen haciendo, al menos, el Fondo de Población de las Naciones Unidas y la Organización Mundial de la Salud ${ }^{14}$.

Los documentos de El Cairo y Beijing han aportado en delinear una base conceptual sobre el contenido de estos derechos y a la vez han avanzado en plantear recomendaciones para que estos tengan concreción en la realidad. El parágrafo 7.3 del Programa de Acción de El Cairo afirma que:

Los derechos reproductivos abarcan ciertos derechos humanos que ya están reconocidos en las leyes nacionales, en los documentos internacionales sobre derechos humanos y en otros documentos pertinentes de las Naciones Unidas aprobados por consenso.

13 Cfr. Rıco, Nieves. Violencia de género: un problema de derechos humanos. Santiago de Chile: Comisión Económica para América Latina y el Caribe. Serie Mujer y DesarroIlo 16, julio de 1996, pp. 13 y ss.

14 Gruskin, Sofia. «Las implicancias conceptuales y prácticas de los derechos reproductivos y sexuales: ¿cuánto hemos avanzado?» En Derechos sexuales y reproductivos. Aportes y diálogos contemporáneos. Lima: Centro de la Mujer Peruana Flora Tristán, 2001, p.10. 
Este mismo texto añade que los derechos reproductivos comprenden:

El reconocimiento del derecho básico de todas las parejas e individuos a decidir libre y responsablemente el número de hijos, el espaciamiento de los nacimientos y el intervalo entre estos y a disponer de la información y de los medios para ello y el derecho a alcanzar el nivel más elevado de salud sexual y reproductiva. También incluye su derecho a adoptar decisiones relativas a la reproducción sin sufrir discriminación, coacciones ni violencia, de conformidad con lo establecido en los documentos de derechos humanos.

Por su parte, la Plataforma de Acción de la IV Conferencia Mundial sobre la Mujer (Beijing, 1995) amplió esta definición al establecer que:

Los derechos sexuales incluyen el derecho humano de la mujer a tener control respecto de su sexualidad, incluida su salud sexual y reproductiva y a decidir libre y responsablemente respecto de esas cuestiones, sin verse sujeta a la coerción, la discriminación y la violencia.

En atención a estos compromisos políticos, Alda Facio afirma que «no se puede hablar de derechos humanos de las mujeres sin hablar de derechos reproductivos, ya que estos son una parte integral de aquellos» ${ }^{15}$.

Teniendo en cuenta estos avances conceptuales, muchos derechos humanos que se encuentran reconocidos en distintos tratados internacionales cobran otra dimensión. Así, la Federación Internacional de Planificación Familiar (IPPF) analiza doce derechos humanos vinculados al campo de la sexualidad y reproducción en el documento que ha denominado Carta de Derechos Sexuales y Reproductivos. Estos derechos son: a la vida, a la integridad física y mental, a no ser sometido a tortura, a la libertad y seguridad personales, a la salud física y mental y al cuidado de la salud, a la igualdad y no discriminación, a casarse y fundar una familia y a la igualdad en ella; a la libertad de pensamiento y de religión, a la privacidad y a la vida familiar, a la información y educación, a los beneficios del progreso científico y a la participación política. Todos estos derechos están contenidos en la Declaración Universal de Derechos Humanos, el Pacto Internacional de Derechos Civiles y Políticos, el Pacto Internacional de

$15 \mathrm{FACIO}, \mathrm{Alda}$. «Asegurando el futuro: las instituciones nacionales de derechos humanos y los derechos reproductivos». En Promoción y defensa de los derechos reproductivos: nuevo reto para las instituciones nacionales de derechos humanos. San José-Costa Rica: Instituto Interamericano de Derechos Humanos, 2003, p.31. 
Derechos Económicos, Sociales y Culturales, la Convención Americana sobre Derechos Humanos, la Convención para la Eliminación de todas las formas de Discriminación contra la Mujer, la Convención sobre Derechos del Niño y la Convención Interamericana para prevenir, sancionar y erradicar la Violencia contra la Mujer.

En el mismo sentido, el estudio introductorio del libro Cuerpo y Derecho ${ }^{16}$ enumera hasta diez derechos que comprenden el universo de derechos reproductivos: el derecho a la vida, a la salud, a la integridad física y estar libre de violencia; a estar libre de explotación sexual; a decidir el número e intervalo de hijos; a la intimidad; a la igualdad y a la no discriminación; al matrimonio y a fundar una familia; al empleo y a la seguridad social y a la educación.

Desde otra aproximación, Marcela Huaita indica que

[...] estos derechos podrían ser clasificados en dos grandes grupos: aquellos relativos a la salud sexual y reproductiva, y aquellos relativos a la autodeterminación sexual y reproductiva. Dentro de los primeros, es decir, aquellos relacionados con el derecho a gozar de salud sexual y reproductiva, se encuentran el derecho a: Servicios de salud sexual y reproductiva integrados y comprensivos; cuidado de la salud materna; maternidad segura; tratamiento y prevención de ITS, VIH/SIDA; anticonceptivos; atención por complicaciones de aborto y en el post aborto y calidad en atención de la salud. Dentro de los segundos, estarían comprendidos aquellos relativos al derecho a la autodeterminación: «unirse conyugalmente o en convivencia; tener hijos, su número, espaciamiento y oportunidad; acceder a tratamiento en casos de infertilidad; tener relaciones sexuales; expresar libremente su sexualidad; consentir informadamente sobre la base de una educación sexual y preservar su integridad corporal (no sufrir violencia, violación, coerción, prácticas dañinas como matrimonios forzados de menores, etcétera $)^{17}$.

De otro lado, si bien los derechos sexuales y reproductivos tienden a ser vistos como dos caras de una misma moneda, en realidad no siempre van

16 CABAL, Luisa y otros. Cuerpo y Derecho. Legislación y jurisprudencia en América Latina. Bogotá-Colombia: Centro Legal para Derechos Reproductivos y Políticas Públicas, Editorial Temis S.A., 2001, pp. 21-43.

17 Huaita, Marcela. «Los derechos sexuales y reproductivos en Iberoamérica, logros y desafíos». Ponencia presentada en el II Congreso Iberoamericano de Derecho Sanitario. Julio 2004, p. 2. 
de la mano pues por ejemplo, existen prácticas sexuales no reproductivas. Alice M.Miller señala al respecto que «la conjunción de los derechos sexuales con los derechos reproductivos ha provocado que los derechos sexuales sean considerados como un subconjunto de los derechos reproductivos». Más adelante, nos indica que "este estatus de subconjunto ha desaparecido a una gama de personas de diferentes edades e identidades sexuales fuera de la norma, además de las prácticas sexuales no reproductivas. Finalmente, nos alerta que «otro resultado de eliminar las actividades sexuales no procreativas y no heterosexuales de la protección de los derechos humanos ha sido dejar estas actividades en el campo de la regulación moral, religiosa o penal» ${ }^{18}$.

$\mathrm{Al}$ respecto, el Relator Especial Paul Hunt observa que «aunque en las dos Conferencias se reconoció que la salud sexual era distinta de la salud reproductiva, no se reconoció de un modo explícito e inequívoco que los derechos sexuales fueran diferentes de los derechos reproductivos». Sin embargo, señala asimismo que

[...] no le cabe duda que una comprensión correcta de los principios fundamentales de los derechos humanos, así como de las normas existentes en esta materia, conduce inevitablemente al reconocimiento de los derechos sexuales como derechos humanos. Entre los derechos sexuales figura el derecho de toda persona a expresar su orientación sexual, teniendo debidamente en cuenta el bienestar y los derechos de los otros, sin temor a persecuciones, privación de libertad o injerencia social. ${ }^{19}$

En consecuencia, podemos afirmar que existe un desarrollo conceptual, sustentado en debates y acuerdos políticos de los Estados parte de las Naciones Unidas, sobre la existencia de los derechos sexuales y los derechos reproductivos, y esta existencia exige que los Estados tomen medidas adecuadas para su efectiva protección.

18 Miller, Alice M. «Sexual no reproductivo: explorando la conjunción y disyunción de los derechos sexuales y reproductivos». En Derechos sexuales y reproductivos. Aportes y diálogos contemporáneos. Lima: Centro de la Mujer Peruana Flora Tristán. Lima, 2001, p. 87.

19 NACIONES UNIDAS. «El derecho de toda persona al disfrute del más alto nivel posible de salud física y mental». Informe del Relator Especial, Sr. Paul Hunt. E/CN.4/2004/49. 16 de febrero de 2004, p. 18. 


\section{Intersecciones entre la violencia contra la mujer y los derechos sexuales y reproductivos: algunas lecciones aprendidas}

En general, al abordar el problema de violencia contra la mujer, este es relacionado con la vulneración del derecho a la vida, la integridad física o psicológica, la seguridad personal, la salud y el libre desarrollo de la personalidad. Sin embargo, al igual que los instrumentos internacionales, la realidad de decenas de miles de mujeres en el mundo, nos indica que muchas de las manifestaciones de violencia contra la mujer afectan también sus derechos sexuales y reproductivos.

Así, en la esfera de la violación de la autodeterminación sexual tenemos a los denominados delitos sexuales o delitos contra la libertad sexual, la trata de personas y la explotación sexual, entre otros. En estos casos, la sexualidad se utiliza como un medio de ejercer poder sobre la víctima; por tanto, al igual que otros actos de violencia, lo que se propone el agresor es someterla, degradarla y humillarla ${ }^{20}$.

De otro lado, existen situaciones que implican además de la trasgresión de su libertad sexual una vulneración de sus derechos reproductivos, tales son los casos de la anticoncepción forzada o bajo amenaza, los abortos contra la voluntad de la mujer, los embarazos y maternidad forzados, la mutilación/ablación genital de la mujer y el matrimonio forzado.

Adicionalmente, en el contexto de un conflicto armado, los actos de violencia sexual pueden ser considerados como crímenes de lesa humanidad. En este sentido, el Tribunal Penal Internacional para Ruanda consideró como crimen de lesa humanidad la violación sexual, entendida como un atentado contra la seguridad de la mujer, e incluyó en su definición el concepto del desnudo forzado y la penetración sexual por la fuerza ${ }^{21}$. Es necesario tener presente también que, en el derecho internacional de los derechos humanos, la violencia sexual constituye un acto de tortura o trato cruel, inhumano o degradante cuando es perpetrado por un agente

20 Callamard, Agnès. Documentar las violaciones de derechos humanos por los agentes del Estado: violencia sexual. Montreal: Derechos y Democracia. Centro Internacional de Derechos Humanos y Desarrollo Democrático, 2002. p. 7.

21 Comisedh-Movimiento Manuela Ramos. «Abusaruwanku. Violación de mujeres: silencio e impunidad. La violencia contra las mujeres en el informe de la Comisión de la Verdad y Reconciliación». Lima, noviembre 2003, pp. 56-57. 
del Estado o toda otra persona en el ejercicio de funciones públicas, a instigación suya o con su consentimiento. Igual sucede con los crímenes de violencia cometidos por miembros de grupos alzados en armas 22 .

A continuación, analizaremos la relación entre tres manifestaciones de violencia contra la mujer y los derechos sexuales y reproductivos, basadas en la experiencia peruana, con miras a esbozar algunos planteamientos para enfrentar estas graves violaciones a los derechos humanos:

\section{LA VIOLENCIA SEXUAL CONTRA LA MUJER EN EL MATRIMONIO}

Una de las agresiones más encubiertas es quizá la violencia sexual que se produce en los lechos matrimoniales o de convivencia. Sus expresiones pueden ser de diverso tipo, desde la imposición de actividades de naturaleza sexual contra la voluntad de la mujer (obligarla a utilizar atuendos determinados para la práctica sexual, por ejemplo) hasta la violación sexual, es decir la práctica coercitiva del acto sexual u otro análogo (coito oral o anal).

Históricamente, este tipo de violencia no solo ha sido tolerada socialmente por hombres y mujeres; sino también sacralizada por las diversas legislaciones nacionales al no sancionarla y considerarla, en el mejor de los casos, como el uso indebido de un derecho. Así lo interpretó, en 1994, la Suprema Corte de Justicia de la Nación de México cuando tres de los cinco magistrados llegaron a la conclusión de que «dentro del matrimonio no podía existir la violación $»^{23}$.

Esta interpretación que, de algún modo, refleja el fundamento central de la exclusión de la violación sexual en el matrimonio como delito por muchos ańos, conlleva el supuesto que por el hecho del matrimonio la mujer pierde su derecho a la libertad y por lo tanto pasa a ser «propiedad» para el uso y disfrute de su cónyuge. Dentro de esta lógica se ubica el tradicional concepto de débito sexual que no es sino la obligación de actividad sexual en el matrimonio y por extensión en las uniones no matrimoniales.

22 Callamard, Agnès. Ob. cit., p.18.

23 Kelly, Patricia. «La violación dentro del matrimonio». El Universal online. México, 20 de noviembre de 2005 < http://www.eluniversal.com.mx/columnas/53521.html >. 
En el Perú, la no criminalización de la violación en el matrimonio estuvo vigente hasta 1991, año en que se aprobó un nuevo Código Penal. Hasta entonces, las mujeres que eran atacadas sexualmente por sus cónyuges no podían denunciar este hecho como delito pues la tipificación del mismo exigía que este se produjera fuera del matrimonio. Así, esta norma legal establecía:

Artículo 196.- Será reprimido con penitenciaría o prisión no menor de dos ańos, el que por violencia o grave amenaza obligara a una mujer a sufrir el acto sexual fuera del matrimonio. (Código Penal de 1924, vigente hasta 1991)

La vigencia de esta disposición no hizo sino reforzar el poder abusivo por parte de la pareja y perpetuar las relaciones de subordinación y de violación de derechos de las mujeres al interior de las relaciones familiares. El cambio posterior de la norma si bien formalmente rompe con esta vocación de impunidad, todavía no logra trasmitir el mensaje que la violación en el matrimonio es un delito. Quizá por ello, los estudios que se realizan en esta materia no reportan casos denunciados penalmente de violencia sexual cometidos por el cónyuge ${ }^{24}$. Lo que sucede en la práctica es que las víctimas de estos delitos siguen callando o recurriendo a normas de naturaleza civil para acabar con esta situación. Entre ellas, la legislación sobre violencia familiar o las disposiciones en materia de separación y divorcio del Código Civil resultan de particular importancia para las mujeres que quieren poner fin a esta situación.

\section{a) Derechos vulnerados}

En los casos de violencia sexual en el matrimonio podemos identificar con claridad la convergencia de la violencia contra la mujer y la violación de sus derechos sexuales y reproductivos. Los derechos vulnerados son por lo tanto:

24 En general, el mayor número de violaciones sexuales reportadas ante instancias públicas -Policía Nacional o Ministerio Público- corresponden a menores de edad. Así lo reportó la Defensoría del Pueblo en una investigación realizada en 1997. El estudio informó que de un total de 6.039 personas que se sometieron a un reconocimiento médico legal en el Instituto de Medicina Legal, para determinar la comisión de un delito contra la libertad sexual, el $91,52 \%$ (5.527) eran menores de edad y $8,48 \%$ (512) personas adultas. En Defensoria del Pueblo. La violencia sexual: un problema de seguridad ciudadana. Las voces de las víctimas. Serie: Informes Defensoriales, N²1. Lima, 2000, pp. 55-56. 
El derecho a una vida libre de violencia: en los términos de la Convención contra la violencia a la mujer, incluye el derecho de la mujer a ser libre de toda forma de discriminación y el derecho a ser valorada y educada libre de patrones estereotipados de comportamientos y prácticas sociales y culturales basadas en conceptos de inferioridad y subordinación.

El derecho a la libertad, seguridad e integridad personales: derechos reconocidos por la Declaración Universal de los derechos humanos, el Pacto Internacional de los Derechos Civiles y Políticos y la Convención Americana de Derechos Humanos. Incluyen el derecho a no ser sometida a torturas ni a tratos crueles, inhumanos o degradantes, «que a su vez incluye el derecho a estar libre de violencia basada en el sexo y el género" ${ }^{25}$.

El derecho a la libertad sexual: que implica el derecho a la autodeterminación sexual, es decir la libertad de decidir todo lo relativo al ejercicio de la sexualidad, incluido el momento y el sujeto con quien compartir la vida sexual.

El derecho a la salud sexual: que en palabras del Relator Especial Hunt constituye «un estado de bienestar físico, emocional, mental y social relacionado con la sexualidad, y no simplemente la ausencia de afecciones, disfunciones o enfermedades; la salud sexual requiere un enfoque positivo y respetuoso de la sexualidad y las relaciones sexuales, así como la posibilidad de gozar de experiencias sexuales agradables y seguras, exentas de coacción, discriminación y violencia» ${ }^{26}$.

Los derechos reproductivos, particularmente el derecho a una maternidad segura: al respecto, la Relatora Especial de las Naciones Unidas sobre violencia contra las mujeres afirmó que «muchas formas de violencia contra la mujer dan lugar a violaciones de sus derechos reproductivos, por cuanto suelen poner en peligro su capacidad reproductiva y/o les impiden que ejerzan opciones reproductivas o sexuales ${ }^{27}$. Es evidente que la violación sexual entrańa una violación a la autodeterminación sexual de la mujer y también a su capacidad reproductiva por el riesgo de un embarazo que esta conlleva.

25 FACIO, Alda. Ob. cit., p. 44.

26 NaCIONeS UnIDAS. Informe del Relator Especial Paul Hunt. Ob. cit., p.18.

$27 \quad$ Ib., p. 45. 
El derecho a la igualdad y no discriminación, mediante el reconocimiento de este derecho toda persona merece igual protección ante la ley y los Estados están obligados a garantizarle que no serán objeto de discriminación por ningún motivo. En el caso analizado, el estado civil se convierte en una categoría de discriminación al excluir a las mujeres casadas de la protección contra la violencia sexual en el matrimonio y, de otro lado, al otorgarles a los cónyuges la prerrogativa marital de atentar sexualmente contra sus parejas.

En consecuencia, la violencia de género como es el caso de la violencia sexual en las relaciones de pareja, además de tratarse de una violación directa del derecho a una vida libre de violencia, constituye también una vulneración de los derechos sexuales y reproductivos de las mujeres y, por lo tanto una grave violación de sus derechos humanos.

\section{b) Lecciones aprendidas}

Como se ha mencionado, en el Perú la violación dentro del matrimonio está considerada dentro de la tipificación general del delito de violación sexual desde 1991:

\section{Artículo 170.- Violación sexual}

El que con violencia o grave amenaza, obliga a una persona a tener acceso carnal por vía vaginal, anal o bucal o realiza otros actos análogos introduciendo objetos o partes del cuerpo por alguna de las dos primeras vías, será reprimido con pena privativa de la libertad no menor de cuatro ni mayor de ocho años ${ }^{28}$.

Es decir, la modificación efectuada —además de ampliar los actos de violencia sexual y de considerar que cualquier persona puede ser víctima de este delito- elimina la condición que se realice "fuera del matrimonio" como lo exigía la derogada norma. Afortunadamente, esta es una tendencia favorable a nivel de la región latinoamericana, así lo reporta un informe elaborado por CLADEM en el que se menciona que salvo en Honduras, donde se excluye expresamente, el abuso sexual en la relación conyugal es incluido en el tipo penal ${ }^{29}$.

28 Código Penal. Edición Oficial, Ministerio de Justicia. Lima-Perú, 2004.

29 VASQUEZ, Roxana e Inés ROMERO. «Balance regional: ¿qué permanece y qué ha cambiado?». En III Seminario Regional Derechos Sexuales, Derechos Reproductivos, Derechos 
Cabe mencionar también el caso mexicano, cuya experiencia en considerar la violación sexual dentro del matrimonio como delito es relativamente reciente. En efecto, recién el 16 de noviembre de 2005, los ministros de la Primera Sala de la Suprema Corte de Justicia de la Nación de México modificaron la Jurisprudencia $N^{\circ} 1^{\mathrm{a}}$./J. 10/94, a fin de dejar establecida la existencia del delito de violación dentro del matrimonio si uno de los cónyuges impone la cópula de manera violenta. De esta manera, la Suprema Corte desechó los criterios que desestimaban la violación en esas circunstancias y, como se ha mencionado antes, que establecían que se trataba solo del ejercicio indebido de un derecho ${ }^{30}$. Con esta resolución se puso fin a la controversia que generaba la anterior jurisprudencia, en la que, en opinión de jueces y organizaciones de mujeres, se atentaba contra la libre determinación de las personas para ejercer su sexualidad.

Estas experiencias, si bien nos muestran cambios positivos en el plano formal, requieren ser redimensionadas y mejoradas a fin que incidan en cambios efectivos en la situación de las mujeres en la relación matrimonial. Son pocas las mujeres adultas que se animan a denunciar un delito de violación sexual y menos aún son las mujeres casadas que denuncian estos atentados contra sus derechos humanos cuando son cometidos por su cónyuge. El cambio de la norma exige, por tanto, la necesaria adopción de políticas públicas que enfrenten claramente el problema de la violencia sexual con programas de información, educación y conciencia social acerca del necesario respeto de los derechos fundamentales de las mujeres, incluido el respeto a su libertad sexual y sus derechos reproductivos. Medidas orientadas a la prevención y atención de la violencia contra la mujer se ubican en este campo.

En esta línea, en el Perú se aprobó el Plan Nacional contra la Violencia a la Mujer 2002-2007, entre cuyos objetivos estratégicos se propone promover cambios en los patrones socioculturales que toleran, legitiman o exacerban la violencia hacia la mujer, en sus diferentes manifestaciones y espacios en los que opera ${ }^{31}$.

Humanos. Comité de América Latina y El Caribe para la Defensa de los Derechos de la Mujer-CLADEM, 2002, p. 95

30 Suprema Corte de Justicia de MÉxico, Dirección General de Comunicación Social. Comunicado de Prensa. México, D.F. 16 de noviembre de 2005 < http://www.scjn.gob.mx>

31 Cfr. Plan Nacional contra la Violencia a la Mujer 2002-2007. Ministerio de la Mujer y Desarrollo Social. Lima-Perú, 2003. 
Para reforzar esta política de Estado es recomendable también considerar la tipificación de la violación sexual dentro del matrimonio como una forma agravada de este delito. Después de tantos años de impunidad e indiferencia estatal frente a estos atentados contra los derechos humanos de las mujeres resulta necesario explicitar claramente la decisión política de combatirlos. Una forma de hacerlo es proyectando el mensaje que los Estados no toleran más este tipo de abusos, a los que consideran de suma gravedad por lo que adoptan respuestas específicas para enfrentarlos también desde el campo penal.

Finalmente, se debe poner atención en que las leyes contra la violencia familiar y las normas civiles que regulan la disolución del vínculo conyugal no sean utilizadas como «mecanismos de encubrimiento» de las situaciones de violencia sexual en el matrimonio. Para tal efecto, debe establecerse la obligatoriedad de las autoridades encargadas de la atención de estos casos (policías, jueces y fiscales) de denunciar las situaciones de violencia sexual cometidos por el cónyuge, cuando estos hechos formen parte de los pedidos de protección frente a situaciones de violencia familiar o constituyan los fundamentos de hecho en demandas de separación judicial o divorcio.

\section{Prácticas COMPULSIVAS de CONTROL REPRODUCTIVO}

En el marco del Programa de Salud Reproductiva y Planificación Familiar 1996-2000, durante el gobierno del Presidente Alberto Fujimori; en el Perú, se produjeron una serie de violaciones a los derechos humanos de las mujeres habiéndose reportado y documentado casos de mujeres esterilizadas sin el debido consentimiento; así como irregularidades en la aplicación de la anticoncepción quirúrgica voluntaria.

En el período 1997-2002, la Defensoría del Pueblo del Perú (DDP) registró 69 quejas relativas a anticoncepción quirúrgica sin consentimiento, de un total general de 781 quejas vinculadas a situaciones de vulneración de los derechos reproductivos. Entre ellas, la práctica de anticoncepción quirúrgica en establecimientos de salud no calificados, requerimiento de autorización del cónyuge para uso de método anticonceptivo, coacción 
para el uso de métodos anticonceptivos y muerte a consecuencia de intervención de anticoncepción quirúrgica ${ }^{32}$.

El primer informe de la DDP sobre anticoncepción quirúrgica voluntaria $^{33}$ identificó los siguientes problemas: i) falta de garantías para la libre elección; ii) impulso de campañas destinadas exclusivamente a la ligadura de trompas y a la vasectomía, con lo que se evidenció que el Estado peruano privilegiaba los métodos definitivos de planificación familiar; iii) falta de seguimiento con posterioridad a la intervención quirúrgica, por lo tanto no se adoptaron las medidas necesarias para evitar complicaciones pos operatorias; iv) la existencia de metas referidas a métodos de planificación familiar, incluidas metas numéricas para los métodos quirúrgicos; $\mathrm{y}, \mathrm{v}$ ) metas de cobertura de anticonceptivos solo para las mujeres.

Entre los casos que llegaron a la DDP está el de la señora María Mamérita Mestanza Chávez, quien fue sometida a un procedimiento quirúrgico de esterilización, que finalmente ocasionó su muerte. Este mismo caso, fue denunciado ante la Comisión Interamericana de Derechos Humanos, por el Comité de América Latina y el Caribe para la Defensa de los Derechos de la Mujer (CLADEM); por el Centro Legal para Derechos Reproductivos y Políticas Públicas (CRLP), el Centro por la Justicia y el Derecho Internacional-(CEJIL), el Estudio para la Defensa de los Derechos de la Mujer-DEMUS y la Asociación Pro Derechos Humanos (APRODEH).

Producto de esta denuncia, finalmente en agosto de 2003, las partes arribaron a un Acuerdo de Solución Amistosa luego de que el Estado peruano reconociera su responsabilidad internacional por violación de los artículos 1.1, 4, 5 y 24 de la Convención Americana sobre Derechos Humanos, así como el artículo 7 de la Convención Interamericana para Prevenir, Sancionar y Erradicar la Violencia contra la Mujer, en agravio de la señora Mestanza Chávez.

32 Cfr. Defensoria del Pueblo. Anticoncepción quirúrgica voluntaria I. Casos investigados por la Defensoria del Pueblo. Serie Informes Defensoriales $N^{\circ} 7$. Lima, enero de 1998. pp.15 y 16. Asimismo: La aplicación de la anticoncepción quirúrgica y los derechos reproductivos III. Casos investigados por la Defensoría del Pueblo. Serie Informes Defensoriales $N^{\circ}$ 69. Lima, octubre de 2002, p. 22.

33 lb., N 7, pp. 40-49. 


\section{a) Derechos vulnerados}

Entre los derechos vulnerados por esta actuación estatal tenemos:

El derecho a la integridad fisica: la esterilización involuntaria o forzosa es una práctica que consiste en el uso del método de control médico de la fertilidad denominado anticoncepción quirúrgica sin contar con el consentimiento de la mujer ${ }^{34}$. Constituye una invasión y agresión contra la integridad personal reconocida por los diversos instrumentos internacionales de derechos humanos y en el caso peruano por el artículo 2 inciso 1) de la Constitución; por lo tanto estamos ante un supuesto de violencia contra la mujer.

El derecho a la vida: en los casos de muerte producidas como resultado de las intervenciones quirúrgicas que no hubieran cumplido con los estándares de calidad aceptados, o de complicaciones que no hubieran sido atendidas con la diligencia debida ${ }^{35}$. Tal fue el caso de la señora Mamerita Mestanza comentado líneas atrás.

El derecho a la libertad sexual y reproductiva: el derecho a decidir cuándo y cuántos hijos tener: la imposición de un método anticonceptivo sin consentimiento de la mujer implica una vulneración a este derecho pues afecta su posibilidad de tomar decisiones en su vida sexual y reproductiva. Es un componente fundamental de los derechos reproductivos el poder tomar decidir cuándo y cuántos hijos tener, por lo que la práctica de ofrecer promociones y primas a los trabajadores de salud para el cumplimiento de metas o cupos de esterilizaciones constituye una grave amenaza de violación de las decisiones autónomas de las mujeres sobre su vida reproductiva. De otro lado, el Estado debe garantizar la libre elección de las personas, por lo que no debe privilegiar o promover un método de planificación familiar sobre los otros.

El derecho a la salud: estas prácticas no solo atentan contra su derecho a la salud reproductiva; sino a su salud en general puesto que ser sometida a una intervención quirúrgica sin consentimiento, al tratarse de un acto de violencia contra la mujer vulnera también su salud física y mental. De los casos recogidos por la DDP son muchas las mujeres que con posterioridad a la

34 Comisión andina de JuRISTAS. Protección de los Derechos Humanos de la Mujer. Estándares Internacionales de protección. Lima-Perú, 2000, p. 139.

35 Defensoria del Pueblo, Informe I, Ob. cit., p. 50. 
práctica de la anticoncepción quirúrgica involuntaria han reportado problemas en la salud mental como depresiones, angustias, pánico e inseguridad.

El derecho a la igualdad y no discriminación: el establecimiento de metas de servicios referidas solo a las mujeres en edad fértil implica un trato discriminatorio hacia ellas pues ignora que las políticas de planificación familiar deben dirigirse a todas las personas; es decir, también a los hombres.

El control de las decisiones reproductivas contra la voluntad de las mujeres constituye de esta manera un grave atentado contra su integridad y contra un conjunto de sus derechos reproductivos, particularmente de su derecho a la libertad de decidir de manera informada el método de planificación familiar que más le convenga u optar por no usar ninguno.

\section{b) Lecciones aprendidas}

El uso de los mecanismos institucionales —nacionales e internacionalesde protección de los derechos de las mujeres ha mostrado ser eficaz para evidenciar y documentar las graves violaciones de los derechos humanos de las mujeres producidas con la práctica de las esterilizaciones forzadas. Así lo ha demostrado la actuación de la DDP al elaborar sus respectivos informes a partir de las quejas que llegaron a su conocimiento. Particular mención merece el primer informe sobre la materia, que puso en evidencia la práctica estatal de presionar o "convencer» a muchas mujeres, particularmente aquellas que vivían en zonas de pobreza y pobreza extrema, para someterse a la anticoncepción quirúrgica.

Las recomendaciones formuladas por la DDP y el seguimiento posterior a las mismas, lograron modificar el enfoque del programa de planificación familiar, eliminando el concepto de «metas» que, en la práctica, era el motor que impulsaba la violación de los derechos de las mujeres. El personal de salud en su afán por cumplir con las metas establecidas, soslayaba la provisión de información completa a las mujeres y su propia voluntad de decisión, pasando a imponerles un método definitivo de control reproductivo.

Otro importante aprendizaje de esta experiencia fue el rol que cumplieron las organizaciones de defensa de derechos de la mujer, particularmente CLADEM-Perú y DEMUS; así como las de derechos humanos nacionales 
e internacionales (APRODEH, CRLP y CEJIL). Esta alianza estratégica, sumada a una eficaz actuación de la Defensoría del Pueblo contribuyó a que el Estado peruano reconociera y asumiera responsabilidad sobre esta práctica violatoria de derechos humanos y arribara a un Acuerdo de Solución Amistosa a partir del caso de la señora Mestanza, en el marco del Sistema Interamericano de Derechos Humanos.

En esta solución amistosa, el Estado peruano además de admitir responsabilidad internacional por los hechos denunciados, se comprometió a adoptar medidas de reparación material y moral por el daño sufrido e impulsar una exhaustiva investigación, tendiente a la sanción de los responsables. Igualmente, se comprometió a adoptar medidas de prevención para evitar que se repitan hechos similares en el futuro.

De otro lado, el Estado peruano asumió el compromiso de efectuar las modificaciones legislativas y de políticas públicas sobre los temas de Salud Reproductiva y Planificación Familiar, eliminando de su contenido cualquier enfoque discriminatorio y respetando la autonomía de las mujeres. Finalmente, se comprometió a adoptar e implementar las recomendaciones formuladas por la Defensoría del Pueblo respecto a políticas públicas sobre salud reproductiva y planificación familiar ${ }^{36}$.

En suma, la interacción entre iniciativas promovidas por las organizaciones de la sociedad civil para la investigación y sanción de las violaciones de los derechos humanos de las mujeres y el funcionamiento eficaz de las entidades nacionales e internacionales de protección de los derechos humanos, ofrece mejores oportunidades de lograr incidencia en los Estados no solo para asumir la responsabilidad por los hechos producidos; sino también, para asumir compromisos orientados a la prevención de futuros hechos violatorios de los derechos de las mujeres.

\section{LA VIOLACIÓN SEXUAL COMO CRIMEN DE LESA HUMANIDAD}

En el año 2001, durante el gobierno de transición dirigido por el Presidente Valentín Paniagua, se creó en el Perú la Comisión de la Verdad y Reconciliación (CVR). Como en todas las experiencias anteriores, la CVR

36 Comisión Interamericana de Derechos Humanos. Acuerdo de Solución Amistosa, Caso $\mathrm{CIDH} \mathrm{N}^{\circ} 12.191 \mathrm{CIDH}$. Maria Mamerita Mestanza Chavez. 
buscó clarificar verdades históricas y pagar tributo a víctimas, no reconocidas como tales previamente, o a sus descendientes. Del mismo modo, buscó documentar prácticas violatorias de los derechos humanos hasta entonces desconocidas por la mayoría de la población ${ }^{37}$. Entre ellas, documentó casos de violencia sexual como una trasgresión grave del Derecho Internacional Humanitario. Esto pudo ser posible pues la experiencia peruana marcó un precedente importante al establecer una unidad de género al interior de la comisión para asegurar la incorporación de la perspectiva de género en el trabajo diario de la CVR. Como resultado de esta decisión el informe final de la CVR incluyó un análisis de la violencia por razones de género; así como un capítulo especial sobre la violencia sexual como crimen de guerra ${ }^{38}$.

El informe de la CVR afirmó que

[...] el Derecho Internacional Humanitario considera que tanto en el conflicto armado internacional (CAI) como en el conflicto armado interno (CANI), la violencia sexual, incluida la violación sexual, transgrede las normas mínimas de humanidad. En el caso del CAI, se señala que la tortura considerada como crimen de guerra incluye los casos de violencia sexual, lo cual se ha hecho explicito en la jurisprudencia de los tribunales penales internacionales y en el Estatuto de Roma. En el caso del CANI, existe consenso para considerar que la trasgresión constituye un crimen de guerra a partir de la jurisprudencia de los tribunales penales para la ex Yugoslavia y para Ruanda y el Estatuto de Roma ${ }^{39}$.

En este sentido, el artículo 7 del Estatuto de la Corte Penal Internacional (CPI) hace un inventario de los crímenes de lesa humanidad e indica que tanto la violación, como la esclavitud sexual, prostitución forzada,

37 Cfr. Hayner, Priscilla B. Unspeakable Truths. Confronting State Terror and Atrocity. New York: Routledge, 2001, p. 17.

38 The World Bank. Gender, Justice and Truth Commissions. June 2006, p.4. En el mismo sentido, se sugiere revisar: MANTILLA, Julissa. «La Comisión de la Verdad y Reconciliación en el Perú y la perspectiva de género: principales logros y hallazgos». Revista del $I I D H, N^{\circ} 43$, Instituto Interamericano de Derechos Humanos, enero-julio 2006. San José-Costa Rica. Una visión más crítica del trabajo de la CVR en el Perú y la perspectiva de género, la podemos encontrar en: GuilLerot, Julie. Gender and Reparations in Perú. International Center for Transitional Justice, IDRC, CRDI < http://www.ictj.org/static/ Americas/Peru/PeruExecSum.pdf $>$.

39 Comisedh - Movimiento Manuela Ramos. Ob. cit., p. 59. 
embarazo forzado, esterilización forzada u otros abusos sexuales de gravedad comparable, son considerados como crímenes de lesa humanidad. En el artículo 8, considera entre los crímenes de guerra a la comisión de actos de violación, esclavitud sexual, prostitución forzada, embarazo forzado, esterilización forzada y cualquier otra forma de violencia sexual que constituya una violación grave de los Convenios de Ginebra ${ }^{40}$.

La CVR reporta que durante el período del conflicto armado (19802000) «se produjeron numerosos actos de violencia sexual contra las mujeres peruanas por agresores provenientes tanto del Estado como de los grupos subversivos $»^{41}$. El mismo informe indica claramente que mientras violaciones a los derechos humanos como tortura, desapariciones, lesiones, muertes en enfrentamientos, detenciones, desapariciones, entre otras, afectaban mayoritariamente a hombres, en el caso de las violaciones sexuales la totalidad de víctimas registradas por la CVR eran mujeres. Cabe mencionar que el registro de la CVR dejaba de lado otras formas de violencia sexual; así, otras formas de abuso sexual, la prostitución forzada, la unión forzada, etcétera ${ }^{42}$.

Ello, en rigor nos indica un sub-registro de situaciones de violencia sexual en contra de las mujeres en el contexto del conflicto armado. Sin embargo, además de este sub-registro, es considerado como otra limitación del informe el hecho que se utilice el término «violación» en lugar de «violencia de género» o incluso "violencia sexual», pues ambas categorías van más allá de la violación y se refieren a otras formas de violencia dirigidas contra las mujeres o tienen un impacto diferenciado sobre ellas (por ejemplo, el aborto forzado, la cohabitación forzada, esterilizaciones forzadas, esclavitud sexual, mutilación sexual, etcétera) ${ }^{43}$.

No obstante ello, el informe de la CVR reporta que la violencia sexual contra las mujeres fue perpetrada tanto por integrantes de los grupos subversivos Sendero Luminoso como del Movimiento Revolucionario Tupac Amaru-MRTA; aunque señala que los testimonios recogidos «no permiten

40 Defensoria del Pueblo: Corte Penal Internacional. Estatuto de Roma. Lima-Perú, 2002, pp. 53 y 60.

41 Comisedh - Movimiento Manuela Ramos. Ob. cit., p. 63.

42 Ib., pp. 63-64.

43 Guillerot, Julie. Ob. cit., p. 4. 
hablar de una práctica sistemática o generalizada, sí se trató de graves transgresiones al Derecho Internacional Humanitario» ${ }^{44}$.

En lo que respecta al Estado como perpetrador de hechos de violencia sexual contra las mujeres, el informe señala que «la CVR tiene evidencias que le permiten concluir que la violencia sexual fue una práctica generalizada y subrepticiamente tolerada, pero en ciertos casos abiertamente permitida por los superiores inmediatos en determinados ámbitos» ${ }^{45}$.

En cuanto al perfil de las víctimas, por el contexto en que se produjo el conflicto armado en el Perú, las víctimas eran en su mayoría mujeres quechua-hablantes, de origen rural, campesinas o amas de casa. En cuanto a su la edad, la CVR informó que la mayor parte de ellas tenían entre 10 y 29 años $^{46}$. Esta caracterización nos indica que fueron las mujeres más jóvenes, excluidas y pobres las que sufrieron estos atentados contra sus derechos humanos.

\section{a) Derechos vulnerados}

Conforme lo afirmó la Relatora Especial sobre la violencia contra la mujer Radhika Coomaraswamy, «la comunidad internacional ha empezado a elaborar normas jurídicas precisas para dejar claro de una vez por todas que la violación y otras clases de violencia por razones de género pueden ser crímenes de guerra, crímenes de lesa humanidad y componentes del crimen de genocidio, así como tortura y otros tratos crueles, inhumanos y degradantes y esclavitud ${ }^{47}$. Entre los derechos vulnerados por la violación sexual como crimen de guerra, tenemos:

Derecho a la vida libre de violencia: como se ha indicado la violencia sexual contra la mujer constituye una manifestación de la violencia de género, por lo tanto atenta contra el derecho a una vida libre de violencia en los términos planteados por la Convención Interamericana contra la

\footnotetext{
Comisedh - Movimiento Manuela Ramos. Ob. cit., p. 88.

Ib.

Ib., p. 65.

7 NACIONES UNIDAS. Integración de los Derechos Humanos de la Mujer y la Perspectiva de Género. Informe de la Sra. Radhika Coomaraswamy, Relatora Especial sobre la violencia contra la mujer, con inclusión de sus causas y consecuencias, presentado de conformidad con la Resolución 2000/45 de la Comisión de Derechos Humanos. E/CN.4/2001/73, 23 de enero de 2001, p. 6.
} 
violencia a la mujer y por otros instrumentos internacionales de protección de los derechos humanos.

Derecho a la integridad y seguridad personales: los testimonios recogidos por la CVR informan que la mayor parte de los actos de violencia sexual cometidos por los grupos subversivos se produjeron durante las incursiones armadas; y en el caso del Estado (ejército y fuerzas policiales) se produjeron fundamentalmente en las zonas de emergencia durante interrogatorios, en operativos de rastrillaje o masacres cometidas por las fuerzas de seguridad. Ello significa que las mujeres que se vieron afectadas por esta grave violación de sus derechos vivían entre dos fuegos, en un contexto de inseguridad agravado por el hecho de no tener la posibilidad de acceder a ningún tipo de protección estatal, dado que agentes del propio Estado eran también perpetradores de las violaciones de sus derechos humanos en aquellas localidades. Asimismo, estamos ante actos violatorios de su derecho a la integridad física, psicológica y sexual.

El derecho a no ser sometida a torturas: muchos testimonios recogidos por la CVR evidencian que en muchos casos, las violaciones sexuales producidas durante el período de conflicto armado en el Perú constituían formas de tortura, trato cruel, inhumano y degradante cometidas fundamentalmente contra la población femenina.

Derecho a la autodeterminación sexual: que implica el ejercicio no coercitivo de la sexualidad. Los hechos recogidos por la CVR constituyen actos vulneratorios del derecho a la libertad sexual en los que los perpetradores trasgredieron las normas mínimas de humanidad recogidas en los Convenios de Ginebra.

Derecho a la salud sexual y reproductiva: el informe de la CVR destacó el dańo sufrido por las mujeres a consecuencia de las violaciones, torturas, abusos sexuales y otros maltratos a los que fueron sometidas por los diferentes actores del conflicto. Todos estos actos vulneran la salud reproductiva entendida como «la capacidad de disfrutar de una vida sexual satisfactoria y sin riesgos y de procrear, y la libertad para decidir hacerlo o no hacerlo, cuándo y con qué frecuencia» ${ }^{48}$.

48 NaCIONeS UnIDAS. Informe del Relator Especial Paul Hunt. Ob. cit., p. 9. 
Derecho a la salud: es evidente que la violencia sexual no solo deja consecuencias físicas en la mujer; sino también afecta su salud mental. El informe de la CVR considera que «en el caso de las mujeres, el impacto en sus subjetividades implica un trauma que es producto de la violencia en general y en particular de aquella sufrida por su condición genérica: violación sexual, abuso sexual, pérdida de la pareja, de los hijos, viudez y desplazamiento ${ }^{49}$.

\section{b) Lecciones aprendidas}

En general los resultados de las Comisiones de la Verdad, ponen en evidencia la necesidad de integrar y transversalizar un enfoque de género desde el diseño mismo de la Comisión hasta las medidas adoptadas para el cumplimiento de sus recomendaciones. En este sentido, el caso peruano, tuvo el acierto de considerar una unidad de género al interior de la estructura de la comisión. Ello permitió incorporar un análisis del impacto diferenciado de la violencia por razones de género, además de incluir un capítulo específico sobre violencia sexual contra las mujeres.

$\mathrm{Al}$ respecto, se reconoce que «a diferencia de experiencias previas, la CVR se constituyó en la primera comisión de la verdad en el mundo en contemplar una perspectiva de género desde el inicio de su trabajo, convirtiéndose así en un significativo precedente para el establecimiento y trabajo de futuras entidades de este tipo" $"$.

Otro aspecto importante a considerar en el trabajo de estas comisiones es la importancia de diferenciar los conceptos de violencia de género o por razones de género, violencia sexual y violación. La experiencia analizada nos indica que si solo se reportan los casos de violación sexual, se deja de lado una serie de abusos sexuales cometidos contra las mujeres y se pierde la dimensión del abuso de poder que ejercen los perpetradores contra sus víctimas, a quienes consideran como meros objetos cuyos cuerpos y voluntades pueden ser utilizados a discreción de los agresores.

Quizá la debilidad más grande del trabajo de la CVR en el Perú es que esta mirada de género no haya logrado ser transversalizada a lo largo de

\footnotetext{
49 Comisedh - Movimiento Manuela Ramos. Ob. cit., p. 51.

50 Mantilla, Julissa. Ob. cit., p. 324.
} 
todo el informe de la Comisión. Así, se ha criticado el carácter «neutral» del lenguaje utilizado en muchas de sus recomendaciones que, en la práctica, invisibiliza los impactos diferenciados de género del conflicto armado y por lo tanto, las situaciones de vulneración de los derechos las mujeres en este contexto ${ }^{51}$. En consecuencia, si bien es un avance focalizar la temática de género al interior de la estructura y funcionamiento de las Comisiones es deseable que el enfoque de género sea transversalizado desde el diseño mismo de estos grupos de trabajo hasta la implementación de sus recomendaciones.

Dado que aún no se ha producido la implementación de las reparaciones, a pesar que desde el mes de julio de 2006 se cuenta con el Reglamento de la Ley 28592 que crea el Plan Integral de Reparaciones-PIR, estamos ante una excelente oportunidad de ponerlo en funcionamiento integrando un enfoque de género. Ello resulta de suma importancia si tenemos en cuenta que «de todas las conductas de violencia sexual mencionadas en el Informe Final de la CVR, solo la violación sexual es incluida dentro del PIR. Esto significa que otros crímenes de violencia sexual como la esclavitud sexual, los embarazos forzados, la prostitución forzada o las uniones forzadas, quedarían excluidas de la reparación ${ }^{52}$. Esta alerta nos plantea importantes desafíos a ser considerados por el Estado peruano y por las organizaciones defensoras de los derechos humanos, pues la reparación y reconciliación requiere ser inclusiva de todas las personas que sufrieron las consecuencias del conflicto armado, entre ellas las mujeres.

\section{Conclusiones}

El análisis de las interacciones entre la violencia contra la mujer y las violaciones de los derechos sexuales y reproductivos nos plantea la importancia de abordar estos problemas desde un enfoque de derechos humanos, que comprende no solo su aproximación conceptual desde una teoría de los derechos humanos; sino también el considerar metodologías y prácticas que sirvan de pauta para el diseño de políticas públicas para enfrentarlos.

51 Guillerot, Julie. Ob. cit., pp. 4 y 7.

52 VAldez ARROYo, Flor de María. «Anotaciones de género al reglamento del PIR». Lima: DEMUS, 2004. 
Las intersecciones entre la violencia contra la mujer y su impacto en los derechos sexuales y reproductivos, resalta la necesidad de transversalizar el enfoque de género desde el análisis, hasta la ejecución de políticas públicas. Ello garantizará el contar con respuestas adecuadas para la prevención, atención y erradicación de este grave problema.

Es indispensable que los avances normativos y acuerdos políticos adoptados en el marco internacional de protección de los derechos humanos de las mujeres, se vean reflejados en los ordenamientos internos desde la propia Constitución, que es la norma suprema de los Estados. Particular importancia tiene para las mujeres el reconocimiento constitucional de su derecho a una vida libre de violencia, sus derechos sexuales y sus derechos reproductivos, estos dos últimos escasamente mencionados por los textos normativos ${ }^{53}$.

A nivel internacional existe un importante desarrollo conceptual de los alcances de los derechos sexuales y reproductivos; sin embargo, este avance reflejado en diversos documentos e informes de las Naciones Unidas, carece de carácter vinculante para los Estados parte. En tal sentido, consideramos importante aprobar una Convención sobre la materia, como lo vienen proponiendo diversas organizaciones de mujeres a lo largo de la región ${ }^{54}$.

Muchas formas de violencia contra la mujer, además de vulnerar sus derechos a una vida libre de violencia, integridad, seguridad y salud; constituyen actos violatorios de sus derechos sexuales, entre ellos a: la autodeterminación sexual, unirse conyugalmente o en convivencia; tener hijos, su número, espaciamiento y oportunidad; acceder a tratamiento en casos de infertilidad; tener relaciones sexuales; expresar libremente su sexualidad; consentir informadamente sobre la base de una educación sexual y preservar su integridad corporal, lo que implica no sufrir violencia, violación o coerción.

53 En América Latina, «los derechos sexuales y reproductivos se encuentran reconocidos, expresamente como tales, por la Constitución de Ecuador. Las constituciones nacionales de Argentina, Brasil, México, Perú, Venezuela y Paraguay consagran el derecho a decidir sobre la planificación familiar, la elección de métodos de anticoncepción y el espaciamiento entre los hijos». En CLADEM. Diez años de avances legales después de El Cairo. Junio 2004. Lima-Perú, p. 17.

54 Cfr. Campaña por una Convención Interamericana de los Derechos Sexuales y Reproductivos. En < www.convencion.org.uy $>$. 
Existen situaciones de violencia contra la mujer que implican además de la trasgresión de su libertad sexual, una vulneración de sus derechos reproductivos. Tales son los casos de la anticoncepción impuesta o bajo amenaza, los abortos contra la voluntad de la mujer, los embarazos y maternidad forzados, la mutilación/ablación genital de la mujer y el matrimonio forzado.

El análisis de las experiencias presentadas evidencia la importancia de hacer visible el impacto de la violencia contra la mujer en sus derechos sexuales y reproductivos. Ello nos permite tomar conciencia de las dimensiones del problema y, en consecuencia, constituye el marco de referencia para la adopción de políticas públicas orientadas a erradicar definitivamente la violencia contra la mujer. 